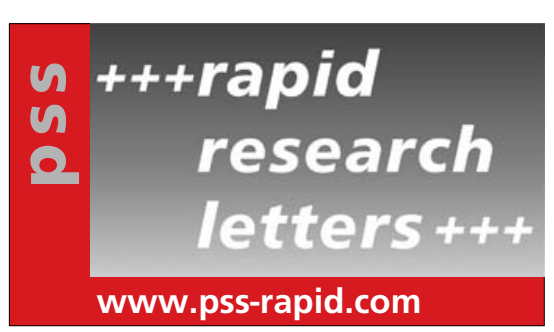

\title{
Optical management in high-efficiency thin-film silicon micromorph solar cells with a silicon oxide based intermediate reflector
}

\author{
Didier Dominé*, Peter BuehImann, Julien Bailat, Adrian Billet, Andrea Feltrin, and Christophe Ballif \\ Institute of Microtechnology (IMT), University of Neuchâtel, Rue A.-L. Breguet 2, 2000 Neuchâtel, Switzerland
}

Received 4 June 2008, revised 24 June 2008, accepted 24 June 2008

Published online 7 July 2008

PACS 68.35.Ct, 78.66.-w, 78.66.Jg, 84.60.Bk, 84.60.Jt

* Corresponding author: e-mail didier.domine@unine.ch, Phone: +41 3271833 12, Fax: +41 327183201

In the effort to increase the stable efficiency of thin film silicon micromorph solar cells, a silicon oxide based intermediate reflector (SOIR) layer is deposited in situ between the component cells of the tandem device. The effectiveness of the SOIR layer in increasing the photo-carrier generation in the a-Si:H top absorber is compared for $\mathrm{p}-\mathrm{i}-\mathrm{n}$ devices deposited on different rough, highly transparent, front $\mathrm{ZnO}$ layers. High haze and low doping level for the front $\mathrm{ZnO}$ strongly enhance the current density $\left(J_{\mathrm{sc}}\right)$ in the $\mu \mathrm{c}-\mathrm{Si}: \mathrm{H}$ bottom cell whereas $J_{\mathrm{sc}}$ in the top cell is influenced by the angular distribution of the transmitted light and by the reflectivity of the SOIR related to different surface roughness. A total $J_{\mathrm{sc}}$ of $26.8 \mathrm{~mA} / \mathrm{cm}^{2}$ and an initial conversion efficiency of $12.6 \%$ are achieved for $1.2 \mathrm{~cm}^{2}$ cells with top and bottom cell thicknesses of $300 \mathrm{~nm}$ and $3 \mu \mathrm{m}$, and without any anti-reflective coating on the glass.
The micromorph solar cell concept consists of an optical and electrical series connection of a high-gap a-Si:H top cell and a low-gap $\mu \mathrm{c}-\mathrm{Si}: \mathrm{H}$ bottom cell. To minimize light-induced degradation, the thickness of the a-Si:H absorber should not exceed $300 \mathrm{~nm}$. This constraint considerably limits the short-circuit current density $\left(J_{\mathrm{sc}}\right)$ on the top cell and, hence, the efficiency of the whole device. Therefore an intermediate reflecting layer (IRL) between the individual cells must be introduced to increase the current in the a-Si:H absorber [1-4].

In this letter, we first analyze the light scattering properties of nano-textured transparent conductive oxide (TCO) layers used as front electrodes for micromorph cells deposited in the superstrate configuration $(\mathrm{p}-\mathrm{i}-\mathrm{n})$. Photocurrents in individual state-of-the-art cells with a $\mathrm{Si}$ oxide based IRL (SOIR) are then compared for front TCOs with different surface morphologies and the observed differences are related to the optical characteristics of these TCOs.

The three types of TCO (type-A, -B and -C) used in this study are as-grown surface textured $\mathrm{ZnO}$ films with two different doping levels obtained by low-pressure chemical vapour deposition (LPCVD) on Schott AF45 glass substrates. The thickness of the resulting layers is adjusted to obtain a sheet resistance below $10 \Omega /$ sq. The root mean square value of their surface roughness $\left(\sigma_{\mathrm{rms}}\right)$ and the correlation length $\xi$ of the textured surface are determined by atomic force microscopy. These characteristics, summarized in Table 1, depend on the thickness of the layers and on the duration of a plasma post-treatment [5] applied to their surface. Note that the type-B $\mathrm{ZnO}$ (without posttreatment), whose sharp V-shape structures prevent good electrical properties of the device [5], is presented only for the sake of light scattering comparisons. The low doping level used for deposition of the thick large-grain $\mathrm{ZnO}$ layers (type-B and -C) provides high transparency in the near infrared (NIR) spectral range because of reduced free carrier absorption (FCA) [6]. The diffuse transmittance in-air of the different TCOs, when light is normally incident to the glass side, is investigated by two methods. First, the haze factor for transmitted light $H_{\mathrm{T}}=T_{\mathrm{dif}} / T_{\text {tot }}$ is calculated from total and diffuse optical transmittance ( $T_{\text {tot }}$ and $T_{\text {dif }}$ ) measurements carried out with a photo-spectrometer equipped with an integration-sphere. Second, the intensity per unit of solid angle scattered at an angle $\theta$ with respect to the direction of an incident laser beam $(633 \mathrm{~nm})$ is de- 
Table 1 Thickness $d$, carrier concentration $N$ [6], surface roughness $\sigma_{\text {rms }}$, correlation length $\xi$, and characteristic morphology of the valleys for the type- $\mathrm{A},-\mathrm{B}$ and $-\mathrm{C}$ front $\mathrm{ZnO}$ layers.

\begin{tabular}{llll}
\hline front ZnO type & A & B & C \\
\hline$d(\mu \mathrm{m})$ & 1.9 & 4.8 & 4.8 \\
$N\left(\mathrm{~cm}^{-3}\right)$ & $1.4 \times 10^{20}$ & $4 \times 10^{19}$ & $4 \times 10^{19}$ \\
$\sigma_{\text {rms }}(\mathrm{nm})$ & 66 & 178 & 165 \\
$\xi(\mu \mathrm{m})$ & 0.4 & 0.8 & 0.8 \\
morphology of valleys & V-shape & V-shape & U-shape \\
\hline
\end{tabular}

termined by angular resolved scattering (ARS) measurement with a rotating photo-detector.

$\mathrm{P}-\mathrm{i}-\mathrm{n}$ micromorph cells and SOIR [3] layers are deposited by very-high frequency plasma enhanced chemical vapour deposition (VHF-PECVD). For the tandem cells presented in the first part of this letter, the top a-Si:H cells are deposited in a KAI-S reactor from OC Oerlikon. The SOIR layers and the bottom $\mu \mathrm{c}-\mathrm{Si}: \mathrm{H}$ cells are then deposited in a laboratory-scale dual chamber VHF-PECVD system. The state-of-the-art micromorph cells presented at the end are fully completed in this dual chamber system. The back contact of the cells consists of a LPCVD ZnO layer covered with a white dielectric reflector [7]. The cell area $\left(\sim 1.2 \mathrm{~cm}^{2}\right)$ is patterned by $\mathrm{SF}_{6}$ plasma etching.

External quantum efficiencies (EQE) of the top and bottom cells $\left(\mathrm{EQE}_{\text {top }}\right.$ and $\left.\mathrm{EQE}_{\mathrm{bot}}\right)$ are measured under red and blue bias-light illumination, respectively. The corresponding $J_{\text {sc }}$ values ( $J_{\text {sc,top }}$ and $J_{\text {sc,bot }}$ ) are calculated from the EQE curves and the AM1.5 g solar spectrum. Current density-voltage $(J-V)$ curves are measured using a dual lamp sun simulator (Wacom) in standard test conditions $\left(25^{\circ} \mathrm{C}\right.$, AM1.5 g spectrum, $\left.100 \mathrm{~mW} / \mathrm{cm}^{2}\right) . J$ is normalised with the $J_{\text {sc }}$ value deduced from the EQE measurements.
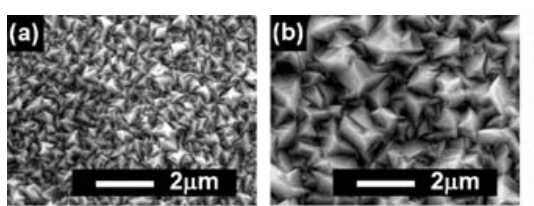

(d)
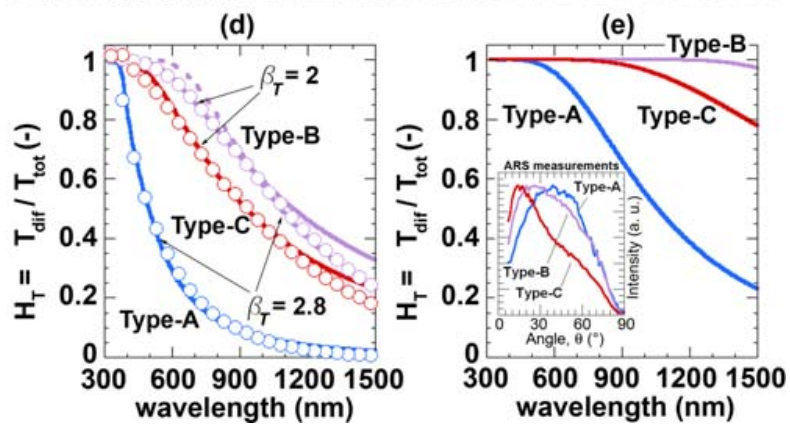

Figure 1 (online colour at: www.pss-rapid.com) (a)-(c) SEM pictures of typical type-A, -B and -C $\mathrm{ZnO}$ layers. Experimental (symbols) and calculated (lines) haze in transmission (d) in air and (e) at the $\mathrm{ZnO} / \mathrm{Si}$ interface for the type- $\mathrm{A},-\mathrm{B}$ and $-\mathrm{C}$ front $\mathrm{ZnO}$ layers. The inset in (e) shows ARS measurements in-air.
For the TCOs presented in Table 1, the experimental haze factors $H_{\mathrm{T}}$ are plotted in Fig. 1(d) as a function of the wavelength $\lambda$ of the transmitted light. The experimental data can be fitted by a function relating $H_{\mathrm{T}}$ to the surface roughness $\sigma_{\mathrm{rms}}[8,9]$ :

$$
H_{\mathrm{T}}(\lambda)=1-\exp \left[-\left(4 \pi \sigma_{\mathrm{rms}} C_{\mathrm{T}}\left|n_{1}-n_{2}\right| / \lambda\right)^{\beta_{\mathrm{T}}}\right]
$$

where $n_{1}$ and $n_{2}$ are the refractive indices of the incident and transmission media, respectively, and $C_{\mathrm{T}}, \beta_{\mathrm{T}}$ are fitting parameters. For the LPCVD ZnO layers used in this study, the fits obtained with $C_{\mathrm{T}}$ between 0.42 and 0.53 are plotted in Fig. 1(a). Defining $\lambda_{\text {eff }}$ as $\lambda /\left|n_{1}-n_{2}\right|$, an almost cubic dependence $\left(\beta_{\mathrm{T}}=2.8\right)$ on the factor $\sigma_{\mathrm{rms}} / \lambda_{\mathrm{eff}}$ in the exponential is found for the type-A $\mathrm{ZnO}$ (small feature size). This is in agreement with Zeman et al. who found a cubic dependence on $\sigma_{\text {rms }} / \lambda_{\text {eff }}$ for $H_{\mathrm{T}}$ of Asahi U-type $\mathrm{SnO}_{2}:$ F layers (similar to type-A $\mathrm{ZnO}$ ) [9], whereas a square dependence and $C_{\mathrm{T}}=0.5$ are predicted by the scalar scattering theory [10]. For type-B and type- $\mathrm{C} \mathrm{ZnO}$ layers (large feature size), $H_{\mathrm{T}}$ is described by a square dependence on $\sigma_{\text {rms }} / \lambda_{\text {eff }}$ for $\lambda<900 \mathrm{~nm}$, as predicted by theory. But for larger $\lambda$, an almost cubic dependence is found again. Note that Stiebig et al. mentioned power factors larger than 3 for $\mathrm{ZnO}$ : Al layers textured by post-etching in $\mathrm{HCl}$ [8].

The spectral dependence of $H_{\mathrm{T}}$ at the internal $\mathrm{ZnO} / \mathrm{Si}$ interface, as calculated from Eq. (1) using $n_{2}=4$ for $\mathrm{Si}$ and values deduced from the measurements in air for $C_{\mathrm{T}}$ and $\beta_{\mathrm{T}}$, are plotted in Fig. 1(e). This indicates that, in a device, more than $65 \%, 95 \%$ and $100 \%$ of the light with $\lambda<900 \mathrm{~nm}$ would be diffused by $\mathrm{ZnO}$ of type-A, -C and -B.

Angular distributions (normalized to their maximum values) of the diffuse light $(\lambda=633 \mathrm{~nm})$ transmitted in air through the TCOs indicate scattering at wider angles for the type-A $\mathrm{ZnO}$ (inset in Fig. 1(e)). Assuming that ARS in air is relevant to predict the $\mathrm{ZnO} / \mathrm{Si}$ internal interface behaviour [11], this more favourable angular distribution offsets the slightly lower $H_{\mathrm{T}}$ value at a $\mathrm{ZnO} / \mathrm{Si}$ interface for $\lambda<900 \mathrm{~nm}$. This explains why the less diffusive type-A $\mathrm{ZnO}$ is more suited for light trapping in a-Si:H single junction solar cells than the type- $\mathrm{C} \mathrm{ZnO}$, as observed in a previous work for the 550-700 $\mathrm{nm}$ spectral range [2].

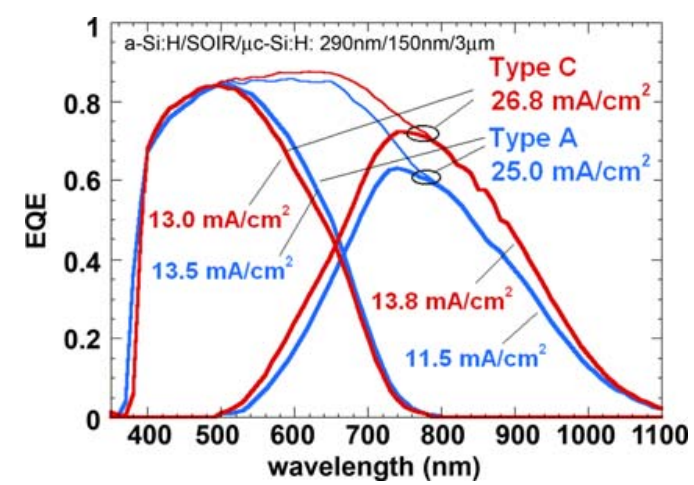

Figure 2 (online colour at: www.pss-rapid.com) EQEs of micromorph cells with $150 \mathrm{~nm}$ thick SOIR layers deposited on type-A and type- $\mathrm{C}$ front $\mathrm{ZnO}$ layers. 


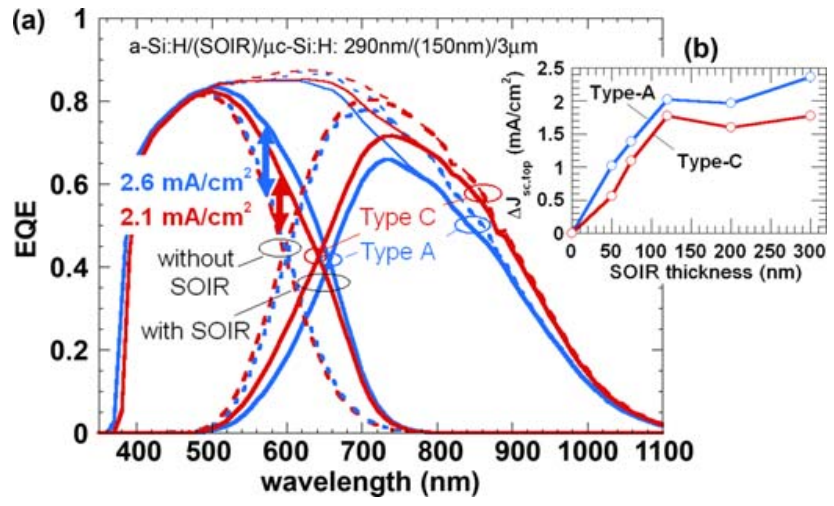

Figure 3 (online colour at: www.pss-rapid.com) (a) EQEs of micromorph cells with and without a $150 \mathrm{~nm}$ thick SOIR deposited on type-A and type-C front $\mathrm{ZnO}$ layers. (b) Gains obtained in $J_{\text {sc,top }}$ for a thickness series of SOIR layers.

EQEs of micromorph tandems deposited on type-A and type-C $\mathrm{ZnO}$ layers, with top cell, SOIR, and bottom cell thicknesses of $290 \mathrm{~nm}, 150 \mathrm{~nm}$, and $3 \mu \mathrm{m}$, respectively, are plotted in Fig. 2. The sum of the $J_{\mathrm{sc}}$ values of the individual cells is increased by $7 \%$ from $25.0 \mathrm{~mA} / \mathrm{cm}^{2}$ to $26.8 \mathrm{~mA} / \mathrm{cm}^{2}$ when the tandem is deposited on the thick $\mathrm{ZnO}$. The gain in EQE occurs in the red and NIR parts of the spectrum as a result of the increased $H_{\mathrm{T}}$ (shown in Fig. 1) and low FCA of the thick and lightly doped type-C $\mathrm{ZnO}$. However, $J_{\mathrm{sc} \text {,top }}$ is smaller for the device deposited on this thicker $\mathrm{ZnO}$ layer. This is examined in the following.

EQEs of four micromorph cells, with and without SOIR, deposited on type-A and type-C $\mathrm{ZnO}$, are plotted in Fig. 3(a). Comparable EQE $E_{\text {top }}$ curves are obtained when no IRL is present. But the gain in $J_{\text {sc,top }}\left(\Delta J_{\text {sc,top }}\right)$ obtained by insertion of the IRL is larger (2.6 instead of $\left.2.1 \mathrm{~mA} / \mathrm{cm}^{2}\right)$ when the tandem is deposited on the type-A (smaller feature size) compared to the type-C $\mathrm{ZnO}$. $\Delta J_{\text {sc,top }}$ versus the thickness of the SOIR layer inserted in devices with top and bottom cell thicknesses of $180 \mathrm{~nm}$ and $1.8 \mu \mathrm{m}$, respectively, is plotted in Fig. 3(b). With the type-A $\mathrm{ZnO}$, $\Delta J_{\text {sc,top }}$ is indeed systematically $\sim 0.5 \mathrm{~mA} / \mathrm{cm}^{2}$ larger than with type-C. The EQE $\mathrm{E}_{\text {top }}$ curves for the two devices without IRL in Fig. 3(a) are almost identical because of the absence of optical interface between the top and bottom cell. Indeed, in this case, light with $\lambda \sim 600 \mathrm{~nm}$ travels only once through the Si layers, making ineffective any better light scattering capability of the front TCO at this wavelength.

These observations indicate that the larger $J_{\text {sc,top }}$ values reported in Fig. 2 and in a previous work [2] when the micromorph with IRL is deposited onto a $\mathrm{ZnO}$ layer with small feature size is caused by a better effectiveness of the IRL. On one hand this is due to a sufficient $H_{\mathrm{T}}(>80 \%)$ at the $\mathrm{TCO} / \mathrm{Si}$ interface in the $550-700 \mathrm{~nm}$ spectral range combined with an improved ARS distribution, as shown in Fig. 1(e) for the type-A $\mathrm{ZnO}$. This combination enhances the light trapping promoted by the IRL in the top cell. On the other hand, difference in steepness of the index change
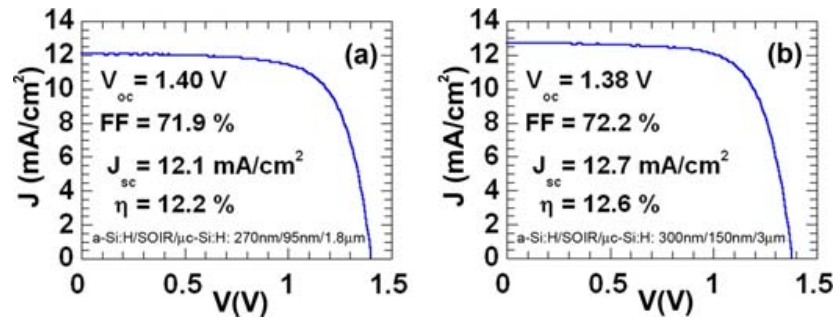

Figure 4 (online colour at: www.pss-rapid.com) $J-V$ curves of $1.2 \mathrm{~cm}^{2}$ state-of-the-art micromorph cells with a bottom cell thickness of (a) $1.8 \mu \mathrm{m}$ and (b) $3.0 \mu \mathrm{m}$.

at the rough $\mathrm{Si} / \mathrm{IRL}$ interface, considered as non abrupt in an effective medium approximation [2], also influences the effectiveness of the IRL. This effect seems less important in view of the similar slopes in $\Delta J_{\text {sc,top }}$ for the two types of $\mathrm{ZnO}$, in Fig. 3(b), with IRLs thicker than $50 \mathrm{~nm}$.

Note that losses by increased total reflectance of the cell are observed when an IRL is inserted [3], as indicated by the sum of $\mathrm{EQE}_{\text {top }}$ and $\mathrm{EQE}_{\mathrm{bot}}$ curves in Fig. 3(a).

For state-of-the-art micromorph cells deposited on type-C $\mathrm{ZnO}$ layers, with a bottom cell thickness of $1.8 \mu \mathrm{m}$ and $3.0 \mu \mathrm{m}$, initial conversion efficiencies of $12.2 \%$ and $12.6 \%$ are achieved, respectively. The $J-V$ characteristics of these micromorph cells are represented in Fig. 4. The thinner device is top limited and provides an open-circuit voltage $V_{\text {oc }}$ of $1.4 \mathrm{~V}$. With the thicker $\mu \mathrm{c}-\mathrm{Si}: \mathrm{H}$ absorber a bottom limited micromorph cell $\left(J_{\mathrm{sc}, \text { top }}=13.3 \mathrm{~mA} / \mathrm{cm}^{2}\right)$ with $J_{\mathrm{sc}}=12.7 \mathrm{~mA} / \mathrm{cm}^{2}$ is obtained.

In summary, a gain in $J_{\text {sc,top }}$ of $2.6 \mathrm{~mA} / \mathrm{cm}^{2}$ is obtained with a SOIR layer deposited in situ. This is comparable to previous results with an ex situ $\mathrm{ZnO}$ layer [2]. This gain depends on the surface morphology of the front TCO and therefore higher $J_{\text {sc,top }}$ values are achieved with the LPCVD $\mathrm{ZnO}$ layer with small feature size. However, when the rougher TCO is used, a remarkably high $26.8 \mathrm{~mA} / \mathrm{cm}^{2}$ value is obtained for the sum of $J_{\mathrm{sc}}$, because of the combined benefits of low FCA and large haze in the NIR. Our best bottom limited micromorph cell $\left(1.2 \mathrm{~cm}^{2}\right)$ with $12.6 \%$ initial conversion efficiency is deposited on this TCO, without any antireflection coating on the glass.

Acknowledgement This work was supported by the Swiss Federal Energy Office (OFEN) (contracts 101191 and 153032) and by the EU (Athlet Project, contract 019670).

\section{References}

[1] D. Fisher et al., Proc. of the $25^{\text {th }}$ IEEE PVSC, 1996, p. 1053.

[2] D. Dominé et al., Proc. of the $4^{\text {th }}$ WCPEC, 2006, p. 1465.

[3] P. Buehlmann et al., Appl. Phys. Lett. 91, 143505 (2007).

[4] K. Yamamoto et al., Prog. Photovoltaics 13, 645 (2005).

[5] J. Bailat et al., Proc. of the $4^{\text {th }}$ WCPEC, 2006, p. 1533.

[6] J. Steinhauser et al., Appl. Phys. Lett. 90, 142107 (2007).

[7] J. Meier et al., Proc. of the $31^{\text {st }}$ IEEE PVSC, 2005, p. 1464.

[8] H. Stiebig et al., Proc. of the $16^{\text {th }}$ EU PVSEC, 2000, p. 549.

[9] M. Zeman et al., J. Appl. Phys. 88, 6436 (2000).

[10] C. K. Carniglia, Opt. Eng. 18, 104 (1979).

[11] J. Krc et al., J. Appl. Phys. 92, 749 (2002). 